\title{
WAVE3 promotes proliferation, migration and invasion via the AKT pathway in pancreatic cancer
}

\author{
SHAOBIN HUANG ${ }^{1 *}$, CHENSONG HUANG $^{1 *}$, WEI CHEN $^{1}$, YIFENG LIU $^{1}$, XIAOYU YIN $^{1}$, JIAMING LAI $^{1}$, \\ LIJIAN LIANG $^{1}$, QIAN WANG ${ }^{1}$, ANXUN WANG $^{2}$ and CHAOXU ZHENG ${ }^{1}$ \\ Departments of ${ }^{1}$ Pancreato-Biliary Surgery and ${ }^{2}$ Oral and Maxillofacial Surgery, \\ The First Affiliated Hospital of Sun Yat-Sen University, Guangzhou, Guangdong 510080, P.R. China
}

Received January 28, 2018; Accepted May 17, 2018

DOI: $10.3892 /$ ijo.2018.4421

\begin{abstract}
Alterations in Wiskott-Aldrich syndrome protein family verprolin-homologous protein 3 (WAVE3) expression play various roles in certain types of cancer. However, the roles of WAVE3 expression in pancreatic cancer remain unknown. The present retrospective study demonstrated that WAVE3 expression was higher in cancerous pancreatic tissues than in non-neoplastic tissues. Moreover, WAVE3 overexpression was related to lymphatic metastasis, a poor differentiation and high pre-operative CA19-9 levels and was an adverse prognostic factor for patients with pancreatic cancer. In vitro, the knockdown of WAVE3 inhibited the proliferative, migratory and invasive potential of pancreatic cancer cells and promoted cell apoptosis. Western blot analysis demonstrated that WAVE3 influenced the protein kinase $\mathrm{B}$ (PBK/AKT) pathway by suppressing the expression of pyruvate dehydrogenase kinase isoform 2 (PDK2) and then negatively inhibiting the phosphorylation of Ser473 on AKT. Furthermore, the expression of AKT pathway downstream proteins [certain epithelialmesenchymal transition (EMT)-related proteins, p53, Bcl-2 and cyclin D1] was accordingly altered. Taken together, our
\end{abstract}

Correspondence to: Professor Chaoxu Zheng, Department of Pancreato-Biliary Surgery, The First Affiliated Hospital of Sun Yat-sen University, 58 Zhongshan Er Road, Guangzhou 510080, P.R. China E-mail: zhengchaoxu@yahoo.com

*Contributed equally

Abbreviations: WAVE3, Wiskott-Aldrich syndrome protein family verprolin-homologous protein 3; MMPs, matrix metalloproteinases; MAPK, mitogen-activated protein kinase; IHC, immunohistochemistry; CCK-8, cell counting kit-8; PBK/AKT, protein kinase B; PDK2, pyruvate dehydrogenase kinase isoform 2; EMT, epithelialmesenchymal transition; PI3K, phosphatidylinositol 3-kinase; PDK1, phosphoinositide-dependent kinase; PBS, phosphate-buffered saline; ANOVA, one-way analysis of variance; ZEB1, zincfinger Ebox binding homeobox 1

Key words: Wiskott-Aldrich syndrome protein family verprolinhomologous protein 3, pancreatic cancer, protein kinase B pathway, proliferation, migration, invasion findings suggest that WAVE3 influences cell proliferation, migration and invasion via the AKT pathway, and targeting WAVE3 and/or the AKT pathway may potentially serve as a treatment strategy for pancreatic cancer.

\section{Introduction}

Pancreatic cancer is a lethal malignant neoplasm, and its morbidity and mortality rates have not noticeably decreased, despite advances in pancreatic cancer treatment strategies. Patients suffering from early-stage pancreatic cancer can be treated by surgery, with a relatively positive outcome. However, the majority of patients are diagnosed at an advanced stage of pancreatic cancer. Recently, clinical trials examining chemotherapy to cure pancreatic cancer have been undertaken to identify a more effective method with which to prolong the life expectancy of patients; however, the long-term curative effects and better choices of different chemotherapeutic combinations remain uncertain (1-3). Moreover, early metastasis is another non-negligible cause of a poor outcome for patients with pancreatic cancer (4). Thus, elucidating the mechanisms responsible for metastasis is probably an important strategy for the treatment of pancreatic cancer.

Wiskott-Aldrich syndrome protein family verprolinhomologous protein 3 (WAVE3) is in the WASP/WAVE family of actin cytoskeleton remodeling proteins. Some researchers have demonstrated that WAVE3 is closely related to cell cytokinesis, motility and proliferation (5). WAVE3 is overexpressed in certain types of cancer, including ovarian cancer (6), breast cancer (7), prostate cancer (8), hepatocellular carcinoma (9), gastric cancer (10), and colorectal cancer (11). High expression levels of WAVE3 are associated with stronger capabilities for migration and invasion in some cancer types, and researchers have discovered that WAVE3 promotes the epithelial-mesenchymal transition (EMT) process to enhance the metastatic potential of certain types of cancer $(10,12)$. Moreover, WAVE3 has also been shown to be associated with cell survival in certain types of cancer $(6,8,10-12)$. The mechanisms through which WAVE3 influences the biological properties of certain types of cancer have been examined in a few studies. For example, WAVE3 has been shown to affect matrix metalloproteinases (MMPs), mitogen-activated protein kinase (MAPK) and Snail $(6,8,10,11,13)$. Thus, WAVE3 
enhances the proliferative, migratory and invasive abilities of cells in certain types of cancer, and similarities and differences exist in the underlying mechanisms. However, whether WAVE3 affects pancreatic cancer and the mechanisms through which it affects the biological characteristics of pancreatic cancer have not yet been determined.

Phosphatidylinositol 3-kinase (PI3K) and protein kinase B (PBK/AKT) are the key proteins in the AKT pathway. This pathway is regulated by multiple mechanisms and is related to a range of diseases, particularly cancer, and pancreatic cancer is no exception. Activated AKT is involved in the proliferative, cycle, growth, survival (also known as anti-apoptosis), migratory and invasive abilities of cells. Phosphoinositide-dependent kinase (PDK1) partially activates AKT via the phosphorylation of T308, and the phosphorylation of S473 by phosphoinositidedependent kinase 2 (PDK2) is needed for full activation $(14,15)$.

In this study, we focused on determining the effects of WAVE3 on the biological behavior of pancreatic cancer and aimed to elucidate the underlying mechanisms of the effect of WAVE3 on pancreatic cancer. The findings of this study may aid in the development of novel treatment strategies targeting WAVE3 and/or the AKT pathway for pancreatic cancer.

\section{Materials and methods}

Patients and samples. A cumulative total of 87 pairs of pancreatic cancer tissues and pancreatic cancer-adjacent non-cancerous samples were collected from patients that underwent radical surgery at the First Affiliated Hospital of Sun Yat-Sen University (Guangzhou, China) from January, 2014 to December, 2015. The patients with pancreatic cancer who suffered from other types of cancer or who received chemotherapy and/or radiotherapy prior to surgery were excluded. Tumor-node-metastasis staging was assessed according to the Cancer Staging Manual (7th edition) of the American Joint Committee on Cancer (16). The tumor grade was detected by pathological sectioning. Overall survival was defined as the period from the date of surgery to the date of death (or the last follow-up). We obtained follow-up survival information by telephone from 79 of the 87 pancreatic cancer patients following surgery. Die to the lack of contact, we were not able to follow-up the remaining 8 patients. The study was approved by the Institute Research Ethics Committee of the First Affiliated Hospital at Sun Yat-Sen University. As this study is a retrospective study, the patient consent was allowed to be waived by the ethics committee.

Immunohistochemistry. The paraffin-embedded tissue sections were first baked in an oven at $60^{\circ} \mathrm{C}$ for $2 \mathrm{~h}$ before being immediately deparaffinized with xylene and rehydrated with diminishing concentrations of alcohol. The endogenous peroxidase activity in the tissues was then blocked with $3 \%$ $\mathrm{H}_{2} \mathrm{O}_{2}$ at room temperature for $15 \mathrm{~min}$. Antigen retrieval was performed at a high temperature in saline sodium citrate (pH 6.0) for $15 \mathrm{~min}$. After slow cooling, the tissue sections were stained with an anti-WAVE3 antibody (1:200, 2806S; Cell Signaling Technology, Danvers, MA, USA) at $4^{\circ} \mathrm{C}$ overnight. After washing with phosphate-buffered saline (PBS), the sections were incubated with HRP-labeled goat anti-rabbit IgG for $15 \mathrm{~min}$ at room temperature (Beyotime, Shanghai,
China), stained with the DAB+ Staining Kit (Gene Tech, Shanghai, China) and counterstained with hematoxylin. Two experienced pathologists independently scored the magnitude of the staining according to the staining intensity and the area that was positive for staining. The score of the positive staining intensity was defined according to the following standards (17): Zero points was assigned to no positive staining, one point was assigned to a light yellow color (weak staining), two points were assigned to a yellow-brown color (moderate staining), and three points were assigned to a brown color (strong staining). For the area of positive staining, tumor cells without positive staining were awarded zero points, those with $30 \%$ positive staining were awarded one point, those with $30-60 \%$ positive staining were awarded two points, and those with $>60 \%$ positive staining were awarded three points. Multiplying the staining intensity score by the score for the positively stained area provided the final immunohistochemistry staining score. The results could then be distinguished by a score of $0,1,2,3,4,6$ or 9 . The median of the scores was statistically analyzed (approximately 4.3), which was equal to 4 . Thus, the cut-off value was 4 . Finally, an immunohistochemistry staining score $\leq 4$ was defined as a tissue with a low WAVE3 expression, while scores $>4$ were defined as having a high WAVE3 expression.

Cells and cell culture. Five pancreatic cancer cell lines (Panc-1, BxPC-3, HPAF-II, SW-1990 and CFPAC-1) and a non-neoplastic human pancreatic ductal epithelial cell line (hTERT-HPNE) were cultured for use in the following experiments. The Panc-1 cells were cultured from an adenocarcinoma at the head of the pancreas, which has been demonstrated to have a better migratory and invasive ability. The CFPAC-1 cells were obtained from a liver metastasis that has been demonstrated to be well-differentiated (18). All the pancreatic cancer cell lines were purchased from the Chinese Academy of Sciences (Beijing, China). The hTERT-HPNE cells were obtained from the prestigious Professor Huang Peng at the Sun Yat-Sen University Cancer Center. The Panc-1 and hTERT-HPNE cells were maintained in DMEM supplemented with 10\% FBS (Gibco/Thermo Fisher Scientific, Waltham, MA, USA), $100 \mathrm{U} / \mathrm{ml}$ penicillin and streptomycin; the CFPAC-1 cells were maintained in Iscove's modified Dulbecco's medium IMDM supplemented with $10 \% \mathrm{FBS}, 100 \mathrm{U} / \mathrm{ml}$ penicillin and streptomycin; the BxPC-3 cells were maintained in RPMI-1640 supplemented with $10 \% \mathrm{FBS}, 100 \mathrm{U} / \mathrm{ml}$ penicillin and streptomycin; the HPAF-II cells were maintained in Eagle's minimal essential medium (EMEM) supplemented with 10\% FBS, $100 \mathrm{U} / \mathrm{ml}$ penicillin and streptomycin; and the SW-1990 cells were maintained in L-15 supplemented with $10 \%$ FBS, $100 \mathrm{U} / \mathrm{ml}$ penicillin and streptomycin. All the cell lines were cultured at $37^{\circ} \mathrm{C}$ in a humidified incubator with $5 \% \mathrm{CO}_{2}$ and used for experiments during the logarithmic growth phase.

Cell transfection. The cells were cultivated in 6-well plates and transfected with WAVE3 siRNA or a negative control siRNA using Lipofectamine ${ }^{\circledR} 3000$ Transfection reagent (Invitrogen, Carlsbad, CA, USA) following the manufacturer's instructions. Briefly, the cells were cultured in an incubator at $37^{\circ} \mathrm{C}$, and after $24 \mathrm{~h}$, the cellular proteins were extracted 
or certain functional experiments were performed (Transwell assays, plate clone formation assay, CCK-8 test, flow cytometry and co-immunoprecipitation). Three candidate WAVE3 siRNA sequences were assessed for the highest interference efficiency by western blot analysis. The WAVE3 siRNA sequences were WAVE3-1 (GGU UUC AAA GAA CAG CAU UTT), WAVE3-2 (GCA AAC AUG CUG AAG ACA UTT), and WAVE3-3 (GCU CUG CCU GAA GGG AUU ATT). The negative control siRNA sequence was sense: UUC UCC GAA CGU GUC ACG UTT. The above-mentioned siRNA sequences were designed by Shanghai GenePharma Co., Ltd. (Shanghai, China).

Western blot analysis. The cells were lysed with a radioimmunoprecipitation assay (RIPA) lysis buffer and PMSF (both from Cell Signaling Technology) for 30 min using a RIPA to PMSF volume ratio of 100:1. For p-AKT 308 and p-AKT 473, the cells were also lysed with Phosphatase Inhibitor Cocktail I (MedChemExpress, Monmouth Junction, NJ, USA). A BCA Protein Assay kit (Thermo Scientific Pierce, Rockford,IL, USA) was used to measure the total protein concentrations. Aliquots $(40 \mu \mathrm{g})$ of total cellular proteins were resolved by SDS-PAGE (5-12\%), electrotransferred onto PVDF membranes and then blocked with 5\% skim milk (w/v) at room temperature for $1 \mathrm{~h}$. The membranes were then incubated with primary antibodies against WAVE3 (1:1,000, 2806S), PI3K (1:1,000, 4249S), AKT $(1: 1,000,4691 S)$, p-AKT 308 (1:1,000, 13038S), p-AKT $473(1: 1,000,4060 S)$ (all from Cell Signaling Technology), PDK2 (1:1,000, ab68164; Abcam, Cambridge, MA, USA), E-Cadherin (1:1,000, 3195S), N-Cadherin (1:1,000, 13116S), Slug (1:500, 9585S), Snail (1:500, 3879S), Vimentin (1:1,000, 5741S), zincfinger Ebox binding homeobox 1 (ZEB1; 1:1,000, 3396S), p53 (1:500, 2527S), Bcl-2 (1:500, 4223S) (all from Cell Signaling Technology), cyclin D1 (1:20,000, ab134175; Abcam) and GAPDH (1:6,000, G8795; Sigma-Aldrich), which served as an internal control on an orbital shaker at $4^{\circ} \mathrm{C}$ overnight, and the secondary antibodies (HRP-labeled goat-anti-mouse (1:1,000, 14709S) and HRP-labeled goat-anti-rabbit (1:1,000, 14708S) (both from Cell Signaling Technology) were added, and the mixtures were incubated for $1 \mathrm{~h}$ at room temperature. The protein-antibody complexes were then detected by chemiluminescence (Pierce ECL Western Blotting Substrate; Thermo Scientific Pierce).

Cell growth curve. The cell lines seeded in medium with $10 \%$ FBS were added to 96 -well plates at a density of $2 \times 10^{3}$ per well. Each cell line consisted of 6 replicate wells per plate and 4 plates. Following incubation at $37^{\circ} \mathrm{C}$ for $24,48,72$ and $96 \mathrm{~h}$, the cell viability in each well was determined using Cell Counting kit (CCK)-8 (Beyotime). The absorbance was then recorded at $450 \mathrm{~nm}$ with a 96-well plate reader (Thermo Fisher Scientific).

Plate clone-forming assay. The cells were cultured with medium containing $10 \%$ FBS in 6-well plates at a density of 500 cells per well at $37^{\circ} \mathrm{C}$ in $5 \% \mathrm{CO}_{2}$. After 14 days, the cell clones were washed with PBS, fixed in $4 \%$ formaldehyde for $15 \mathrm{~min}$, and stained with crystal violet. The number of stained cell clones with diameters larger than $1 \mathrm{~mm}$ were counted and analyzed as previously described.
Cell apoptosis and cell cycle analysis. According to the instructions supplied with the eGFP Annexin V and PI Apoptosis kit (GeneCopoeia, Inc., Rockville, MD, USA), eGFP Annexin V and PI double staining and flow cytometry were conducted to analyze cell apoptosis. The pancreatic cancer cell lines (Panc-1 and CFPAC-1) were plated in 6-well plates $\left(1 \times 10^{6}\right.$ cells/well) and harvested after a $24 \mathrm{~h}$ of incubation. The cells were washed with PBS at pH 7.4 and centrifuged at $110 \mathrm{x}$ g for $5 \mathrm{~min}, 3$ times. Single-cell suspensions were then resuspended in $500 \mu \mathrm{l}$ of binding buffer containing $5 \mu \mathrm{l}$ of eGFP Annexin V and $2 \mu \mathrm{l}$ of PI in the dark for $15 \mathrm{~min}$. Cell apoptosis was analyzed by flow cytometry using FlowJo 7.6 (Tree Star, Inc., Ashland, OR, USA) software.

The cells were collected as described above. After washing 3 times with PBS, the cells were resuspended in cold PBS, fixed in $70 \%$ ethanol, and stored at $4^{\circ} \mathrm{C}$ for $30 \mathrm{~min}$. The cells were centrifuged at $110 \mathrm{x} \mathrm{g}$ for $5 \mathrm{~min}$, resuspended in $500 \mu \mathrm{l}$ of PI $(50 \mu \mathrm{g} / \mathrm{ml})$ and then incubated on ice in the dark for $15 \mathrm{~min}$. Cell cycle analysis was conducted by flow cytometry and analyzed using ModFit LT 4.1 (Verity Software House, Topsham, ME, USA) software.

Wound healing assays. The cells were cultivated in 6-well plates at a density of $1 \times 10^{6}$ cells per well. The cells were cultured in medium containing $10 \% \mathrm{FBS}$ for $24 \mathrm{~h}$ at $37^{\circ} \mathrm{C}$ and $5 \% \mathrm{CO}_{2}$. A scratch wound was then created by introducing a vertical line on the cell surface with a $200-\mu 1$ plastic pipette tip. Cell debris was removed by washing 3 times with PBS, followed by the addition of medium containing $1 \%$ FBS and mitomycin C (MedChemExpress). A region with a defined area within the scratch was imaged using a microscope equipped with a digital camera at one $(0 \mathrm{~h}), 24$ and $48 \mathrm{~h}$. The length of the scratch was measured using Image-Pro Plus 6.0. The migration rate was calculated as follows: $(\%$ at $0 \mathrm{~h})=(\mathrm{D} 0-\mathrm{DT}) / \mathrm{D} 0$ $\mathrm{x} 100 \%$ (D0, distance measured at $0 \mathrm{~h}$; DT, distance measured at 24 or $48 \mathrm{~h}$ ).

Transwell migration and invasion assays. The tumor cell migration and invasion potentials were determined using Transwell ${ }^{\circledR}$ chambers $(8 \mu \mathrm{m}$; Corning, Corning, NY, USA, BioCoat Control Cell Culture Inserts and BioCoat Matrigel Invasion Chambers). Three independent experiments were conducted under the same conditions. The upper Boyden chambers, containing serum-free medium, were seeded with $2 \times 10^{5}$ cells (for migration), while $5 \times 10^{5}$ cells were seeded in the upper membranes with serum-free medium (for invasion). Subsequently, $600 \mu 1$ of medium containing $20 \%$ FBS was added to the lower chamber. The cells were cultured in a $37^{\circ} \mathrm{C}$ incubator with $5 \% \mathrm{CO}_{2}$. Twenty-four hours later, the cells were washed 3 times with PBS and fixed in $4 \%$ formaldehyde for $10 \mathrm{~min}$. Non-invading cells in the upper chamber (for migration) or on the upper membrane (for invasion) were removed carefully with a cotton swab, and the cells were then washed again 3 times with PBS. The cells that adhered to the lower surface of the upper chamber (for migration) or the upper membrane (for invasion) were stained with $0.1 \%$ crystal violet. Ten randomly selected fields of fixed cells at x 200 magnification were captured using the microscope equipped with a digital camera, and the numbers of cells that were stained 
purple were counted. The numbers of cells in the different groups were statistically analyzed as previously described.

Statistical analysis. All statistical analyses were conducted using SPSS for Windows, version 20.0 (SPSS, Inc., Chicago, IL, USA). The significance of the results obtained for the different groups was analyzed by the Student's t-test and one-way analysis of variance (ANOVA) followed by appropriate post hoc tests (Fishers' Least Significant Difference). Differences between categorical variables were compared using the Chi square test, while when the number of variables was $<5$, Fisher's exact test was used to detect the difference. The survival curve was calculated using the Kaplan-Meier method and analyzed with the log-rank test using GraphPad Prism 6 (GraphPad Software, San Diego, CA, USA). In all the statistical analyses, statistical significance was set as $\mathrm{P}<0.05$.

\section{Results}

Association between WAVE3 expression and the clinicopathological characteristics of patients with pancreatic cancer. To determine the role of WAVE3 protein expression in the development of pancreatic cancer, the association between the clinicopathological characteristics of the patients with pancreatic cancer and WAVE3 protein expression was analyzed. The data presented in Table I demonstrate that a high expression level of WAVE3 was associated with lymphatic metastasis $(\mathrm{P}<0.05)$, poorly differentiated tumors $(\mathrm{P}<0.05)$ and high pre-operative CA19-9 levels $(\mathrm{P}<0.05)$. There were no obvious associations between WAVE3 protein expression and sex $(\mathrm{P}=0.2535)$, age $(\mathrm{P}=0.2555)$, distant metastasis $(\mathrm{P}=0.2775)$, pre-operative CA125 $(\mathrm{P}=0.5564)$ and CEA $(\mathrm{P}=0.7736)$ levels, smoking history $(\mathrm{P}=0.4193)$, history of alcohol consumption $(\mathrm{P}=0.5747)$ or clinical stage $(\mathrm{P}=0.7469)$, while in clinical stage II, there was no evidence that single tumors with vascular invasion (T2a) or multiple tumors with or without vascular invasion (T2b) were related to WAVE3 expression $(\mathrm{P}=0.2833)$.

Varying expression levels of WAVE3 in pancreatic cancer tissues and adjacent non-cancerous tissues. A positive WAVE3 protein expression was obseved in the cytoplasm of pancreatic cancer cell tissues (Fig. 1B-F), while in the adjacent non-cancerous tissues, a low or scarce WAVE3 protein expression was detected (Fig. 1A). Moreover, the immunostaining scores for WAVE3 protein expression in the pancreatic cancer tissues were significantly higher than those in the non-cancerous tissues (Fig. 2A). Among the pancreatic cancer cases, the levels of WAVE3 expression were lower in the well-differentiated adenocarcinomas than in the poorly differentiated adenocarcinomas (Fig. 2B). Furthermore, the WAVE3 protein levels were prominently higher in the pancreatic cancer cases with higher pre-operative CA19-9 levels and lymphatic metastasis than in those without these characteristics (Fig. 2C and D).

The prognostic value of WAVE3 expression in patients with pancreatic cancer. To elucidate the prognostic value of WAVE3 in patients pancreatic cancer, the associations of WAVE3 expression with survival time and recurrence-free survival time were detected in 79 of the 87 pancreatic cancer
Table I. Association of WAVE3 expression with the clinicopathological characteristics of the patients with pancreatic cancer.

\begin{tabular}{|c|c|c|c|}
\hline \multirow[b]{2}{*}{ Characteristics } & \multicolumn{2}{|c|}{ WAVE3 expression } & \multirow[b]{2}{*}{$\mathrm{P}$-value } \\
\hline & High & Low & \\
\hline Sex & & & 0.2535 \\
\hline Male & 31 & 24 & \\
\hline Female & 22 & 10 & \\
\hline $\operatorname{Age}^{\mathrm{b}}$ & & & 0.2555 \\
\hline$\geq 62$ & 30 & 15 & \\
\hline$<62$ & 23 & 19 & \\
\hline Lymphatic metastasis & & & 0.0004 \\
\hline Negative & 27 & 30 & \\
\hline Positive & 26 & 4 & \\
\hline Distant metastasis & & & 0.2775 \\
\hline Negative & 50 & 34 & \\
\hline Positive & 3 & 0 & \\
\hline Clinical stage & & & 0.7469 \\
\hline I & 9 & 9 & \\
\hline II & 40 & 23 & 0.2833 \\
\hline $\mathrm{T} 2 \mathrm{a}$ & 17 & 13 & \\
\hline $\mathrm{T} 2 \mathrm{~b}$ & 23 & 10 & \\
\hline III & 3 & 2 & \\
\hline IV & 1 & 0 & \\
\hline Differentiation & & & $<0.0001$ \\
\hline Poor & 25 & 2 & \\
\hline Moderate & 28 & 25 & \\
\hline Well & 0 & 7 & \\
\hline Pre-surgery level of CA19-9 ${ }^{c}$ & & & $<0.0001$ \\
\hline High & 49 & 16 & \\
\hline Low & 4 & 18 & \\
\hline Pre-surgery level of CA $125^{\mathrm{d}}$ & & & 0.5564 \\
\hline High & 9 & 4 & \\
\hline Low & 44 & 30 & \\
\hline Pre-surgery level of $\mathrm{CEA}^{\mathrm{e}}$ & & & 0.7736 \\
\hline High & 10 & 5 & \\
\hline Low & 43 & 29 & \\
\hline Smoking history & & & 0.4193 \\
\hline Yes & 15 & 7 & \\
\hline No & 38 & 27 & \\
\hline History of alcohol consumption & & & 0.5747 \\
\hline Yes & 12 & 6 & \\
\hline No & 41 & 28 & \\
\hline
\end{tabular}

${ }^{a}$ Differences between categorical variables were compared using the Chi-square test, and when the number of variables was $<5$, Fisher's exact test was used to detect the difference; ${ }^{b}$ age, the median age of the pancreatic cancer patients was 62 ; ${ }^{\mathrm{C}} \mathrm{CA} 19-9>37 \mathrm{U} / \mathrm{ml}$ was classified as high, and CA19-9 $\leq 37 \mathrm{U} / \mathrm{ml}$ was classified as low; ${ }^{\mathrm{d}} \mathrm{CA} 125>35 \mathrm{U} / \mathrm{ml}$ was classified as high, and CA $125 \leq 35 \mathrm{U} / \mathrm{ml}$ was classified as low; ${ }^{\mathrm{e}} \mathrm{CEA}>5 \mathrm{ng} / \mathrm{ml}$ was classified as high, and CEA $\leq 5 \mathrm{ng} / \mathrm{ml}$ was classified as low. 

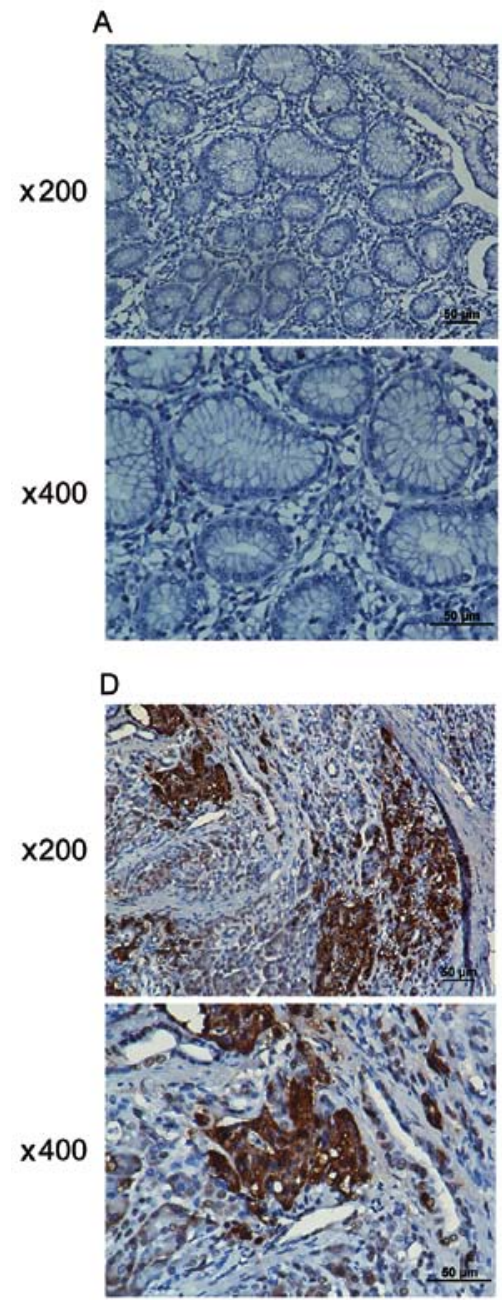

B
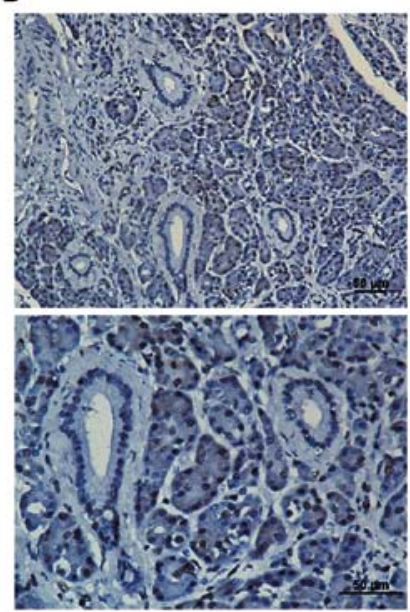

$\mathrm{E}$

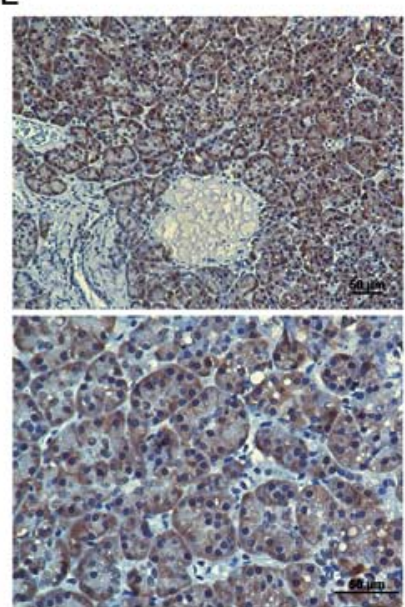

C
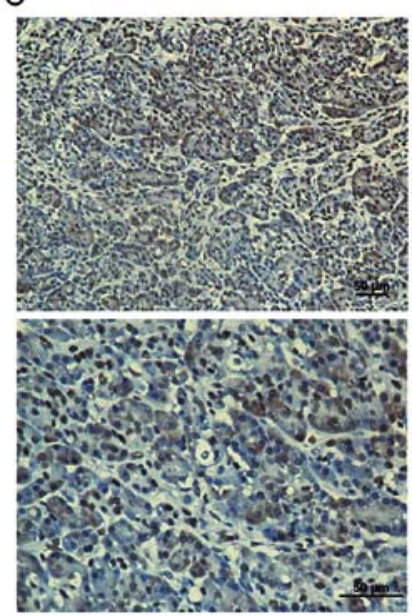

$\mathrm{F}$

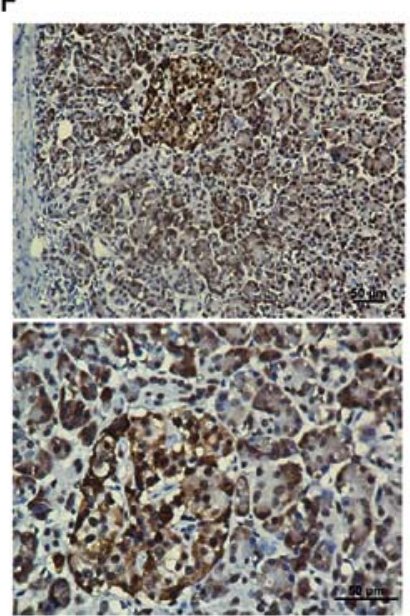

Figure 1. Differential expression levels of WAVE3 in pancreatic cancer tissues and adjacent non-cancerous tissues as shown by immunohistochemistry. (A) Adjacent non-cancerous tissues. (B) Pancreatic cancer detected as well-differentiated adenocarcinoma. (C) Pancreatic cancer detected as moderately differentiated adenocarcinoma. (D) Pancreatic cancer detected as poorly differentiated adenocarcinoma. (E) Pancreatic cancer detected as well-differentiated adenocarcinoma with a higher pre-operative CA19-9 level. (F) Pancreatic cancer detected as moderately differentiated adenocarcinoma with lymphatic metastasis. Images captured at x200 and x400 magnification under a microscope. WAVE3, Wiskott-Aldrich syndrome protein family verprolin-homologous protein $\approx 3$.
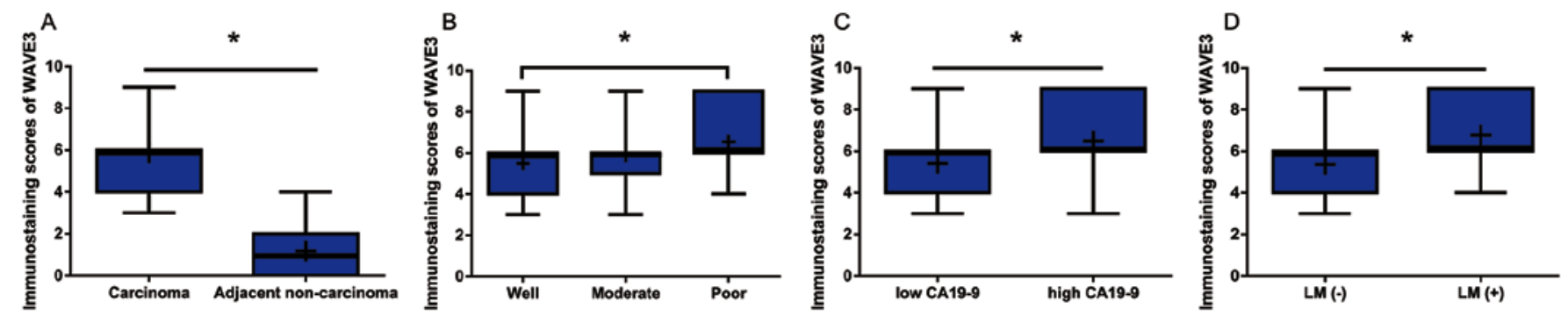

Figure 2. Abnormal WAVE3 expression in patients with pancreatic cancer. (A) Box plots are presented to compare the expression of WAVE3 between pancreatic cancer tissues and adjacent non-cancerous tissues. (B) Differences in WAVE3 expression with different tumor differentiations. (C) Difference in WAVE3 expression between low pre-operative CA19-9 and high pre-operative CA19-9 levels in pancreatic cancer. (D) Expression of WAVE3 in pancreatic cancer cases with or without lymphatic metastasis (LM). The boxes represent $25-75 \%$ of the observations. The median is indicated by the bold lines, and the mean is indicated by the ' + '. "P<0.05. WAVE3, Wiskott-Aldrich syndrome protein family verprolin-homologous protein 3.

patients. As shown in Fig. 3A, a prominent difference in the overall survival between the low WAVE3 expression group (median survival time, 16.0 months) and the high WAVE3 expression group (median survival time, 5.0 months; $\mathrm{P}<0.05$ ) was observed. As shown in Fig. 3B, a significant difference in recurrence-free survival between the low WAVE3 expression group (median recurrence free survival time, 12.0 months) and the high WAVE3 expression group (median recurrence free survival time, 5.0 months; $\mathrm{P}<0.05$ ).

High expression of WAVE3 in pancreatic cancer cell lines. The pancreatic cancer cell lines, BxPC-3, CFPAC-1, PANC-1, 

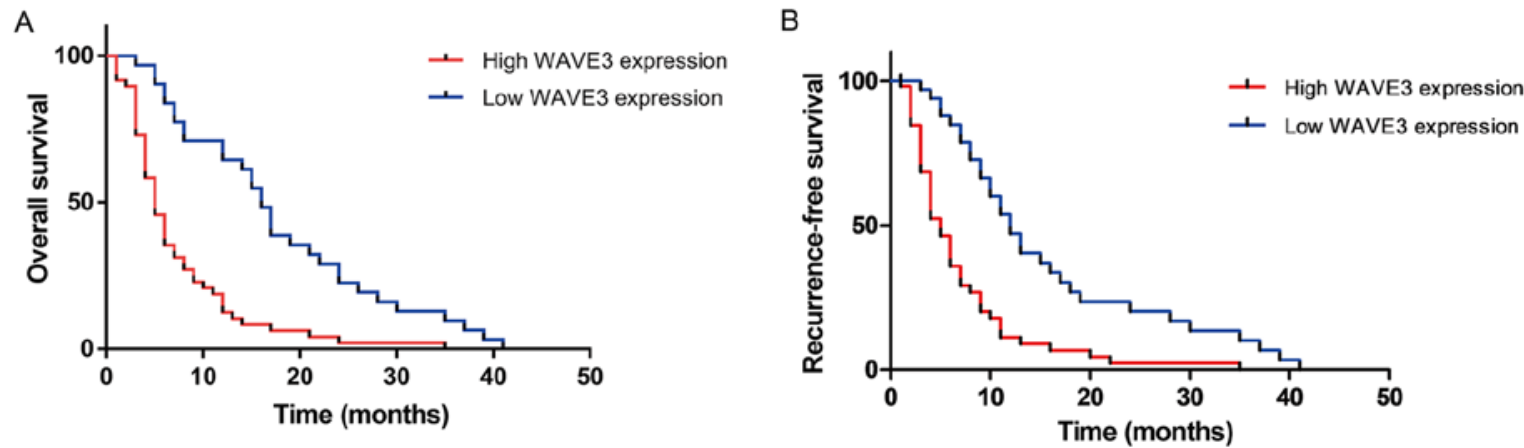

Figure 3. The effect of WAVE3 expression on the prognosis of patients with pancreatic cancer. (A and B) Survival curve showing the prominent difference in overall survival and recurrence-free survival between the low WAVE3 expression group and the high WAVE3 expression group (P<0.05). WAVE3, Wiskott-Aldrich syndrome protein family verprolin-homologous protein 3.
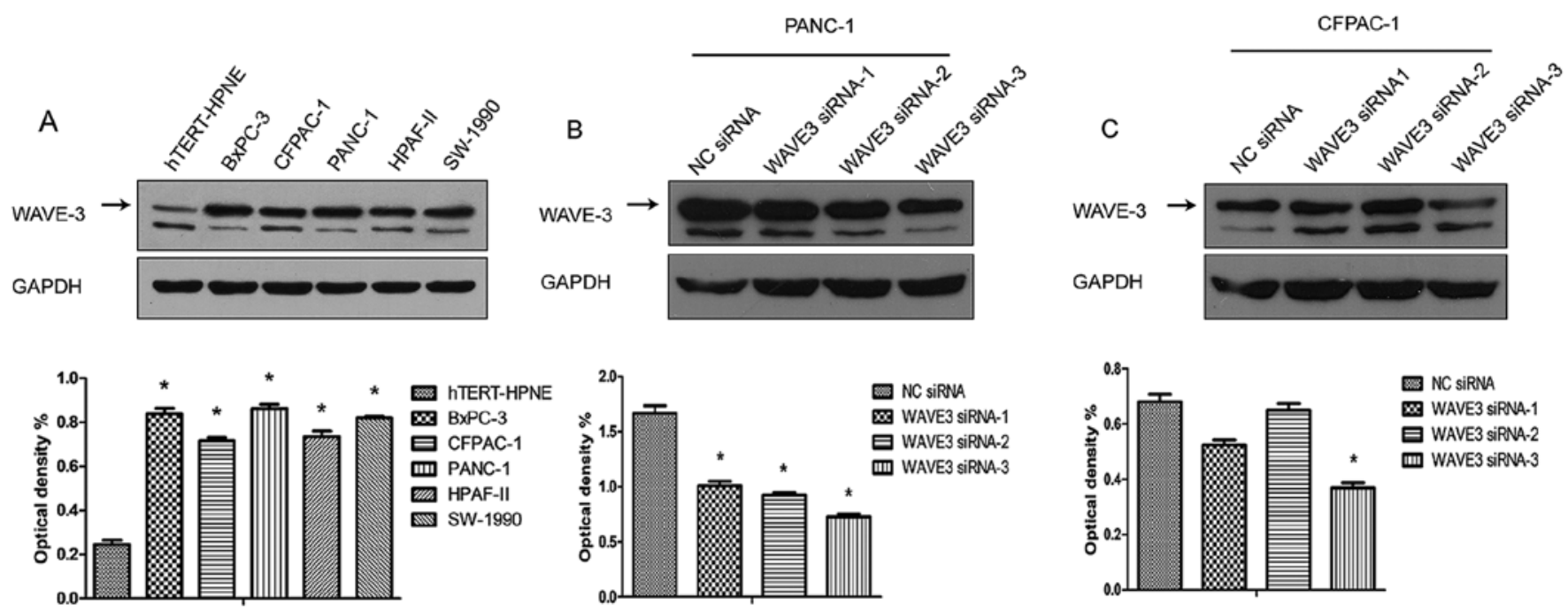

Figure 4. WAVE3 expression in different cell lines and following WAVE3 siRNA interference. (A) Difference in WAVE3 expression between the pancreatic cancer cell lines and a non-neoplastic human pancreatic ductal epithelial cell line (hTERT-HPNE). (B and C) The WAVE3 expression level was decreased to a much greater extent in the WAVE3 siRNA-transfected pancreatic cancer cells lines (PANC-1 and CFPAC-1) compared to that in their negative control siRNA (NC siRNA)-transfected counterparts, particularly with Si-3. "P<0.05/(n-1), $\mathrm{n}$ means the number of groups vs. the hTERT-HPNE cells or the NC siRNA-transfected cells. WAVE3, Wiskott-Aldrich syndrome protein family verprolin-homologous protein 3.

HPAF-II and SW-1990, and a non-neoplastic human pancreatic ductal epithelial cell line (hTERT-HPNE) were cultured, and the protein expression of WAVE3 was detected in different cells types by western blot analysis. The results demonstrated that the WAVE3 expression levels were much higher in the pancreatic cancer cell lines than in the non-neoplastic human pancreatic ductal epithelial cell line (hTERT-HPNE). In addition, the different pancreatic cancer cell lines presented differential levels of WAVE3 protein expression. A previous study demonstrated that the PANC-1 cells exhibited better migratory and invasive abilities, while the CFPAC- 1 cells were shown to be well-differentiated (18). In this study, PANC-1 expressed relatively higher WAVE3 protein levels, while the CFPAC-1 cells presented lower WAVE3 protein levels (Fig. 4A). Thus, the PANC-1 and CFPAC-1 were selected for use in the following experiments. The protein expression of WAVE3 was knocked down by WAVE3 SiRNA in both the PANC-1 and CFPAC-1 cell lines. Three different sequences of WAVE3 siRNA ( $\mathrm{Si}-1, \mathrm{Si}-2$ and $\mathrm{Si}-3$ ) were used to knock down its expression. The results demonstrated that $\mathrm{Si}-3$ was the most effective siRNA. The expression level of WAVE3 was decreased in both the PANC-1 and CFPAC- 1 cell lines following WAVE3 siRNA interference (Fig. 4B and C).

Knockdown of WAVE3 inhibits the migratory and invasive potentials of pancreatic cancer cells. The expression of WAVE3 in the PANC-1 and CFPAC-1 cell lines was knocked down by transfection with WAVE3 siRNA ( $\mathrm{Si}-3$ ). Wound healing and Transwell (migration and invasion) assays were then conducted to determine the invasive and metastastic potentials of the pancreatic cancer cells with or without transfection. Following RNA interference, the PANC-1 and CFPAC-1 cell lines displayed weakened cell migratory and invasive capabilities compared with the control group $(\mathrm{P}<0.05)($ Fig. 5A-C). We also observed that the expression levels of certain EMT-related proteins were altered after the knockdown of the expression of WAVE3 in the PANC-1 and CFPAC-1 cell lines. As indicated, the expression levels of certain EMT-related proteins, such as Slug, Snail, Vimentin, ZEB1 and N-Cadherin, were predominantly decreased, while E-cadherin protein expression 
A

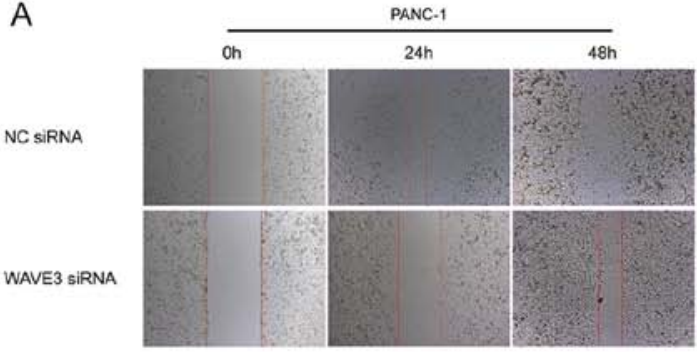

CFPAC-1

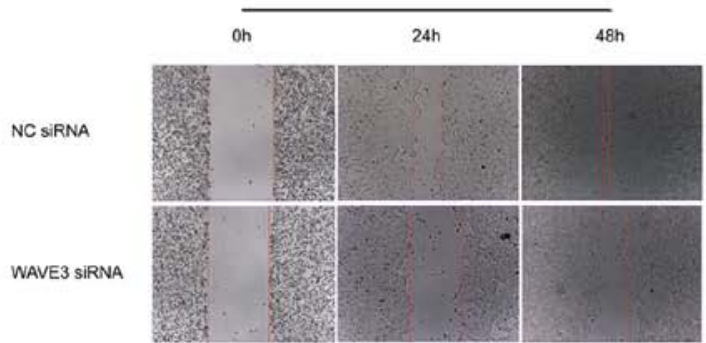

B
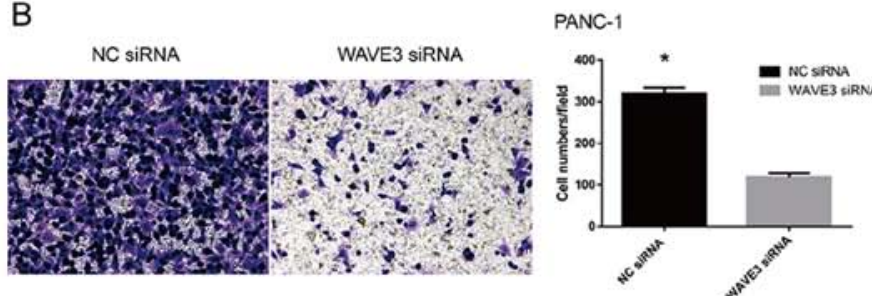

C

C NC SiRNA
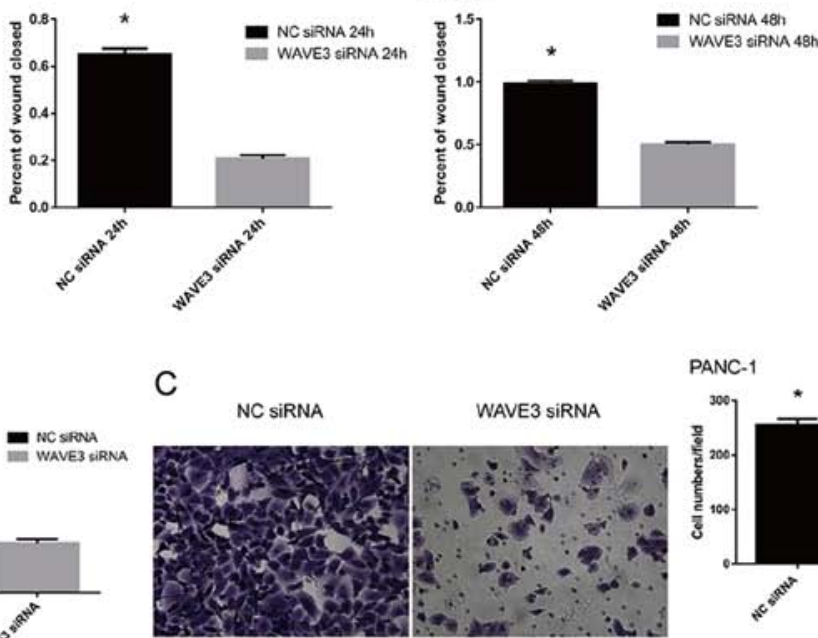

CFPAC-1

PANC- 1

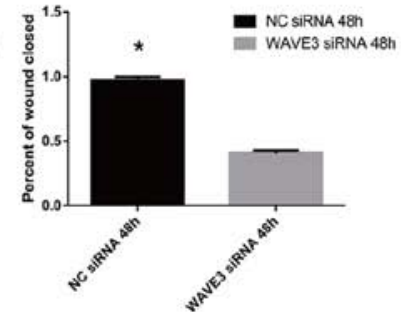

PANC-1
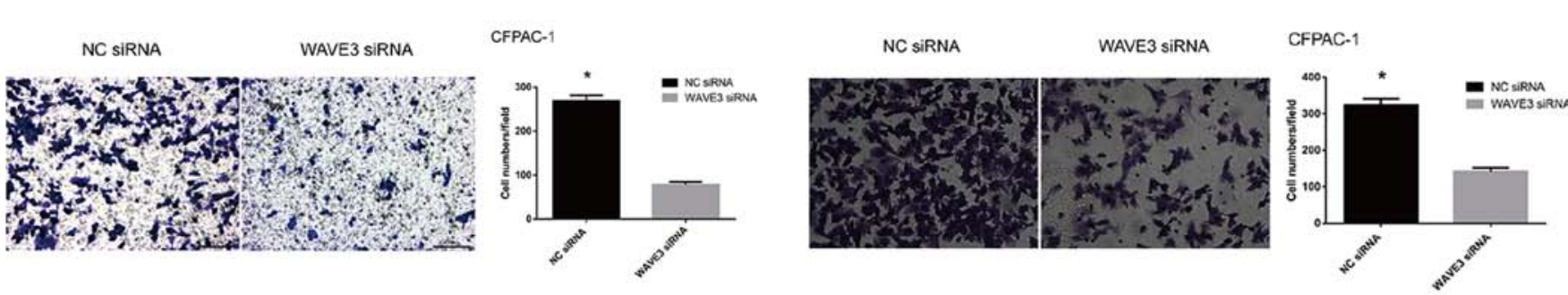

D
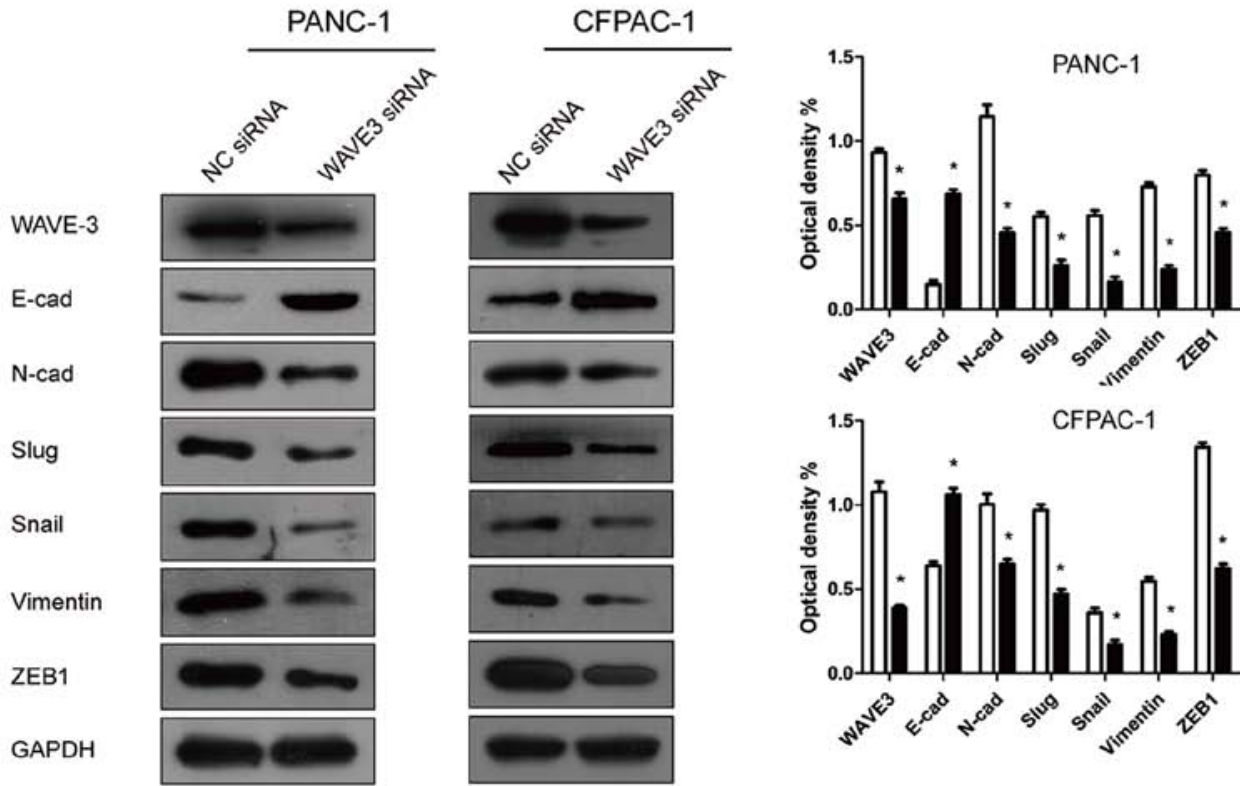

$\square$ NC SIRNA

WAVE3 siRNA

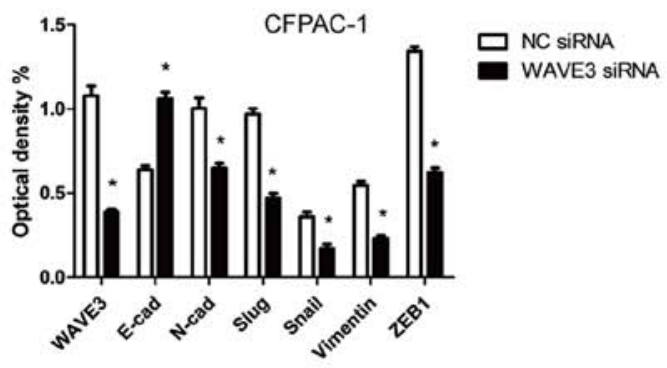

Figure 5. Knockdown of WAVE3 suppresses the migratory and invasive potentials of the cells by influencing the EMT process in the PANC-1 and CFPAC-1 cell lines. (A and B) Wound healing (magnification, x50) and Transwell migration (magnification, x200) assays indicated that WAVE3 knockdown suppressed the migratory capabilities of pancreatic cancer cells ( $\mathrm{P}<0.05$ vs. the NC siRNA-transfected cells). (C) Transwell invasion assays (magnification, $\mathrm{x} 200$ ) showed that the invasion potentials were decreased in the cells in which WAVE3 was knocked down compared with the controls ("P $<0.05$ vs. the NC siRNA-transfected cells). (D) WAVE3 suppression affected EMT, resulting in the acquirement of an epithelial-like phenotype in the pancreatic cancer cell lines. " $\mathrm{P}<0.05$ vs. the NC siRNA-transfected cells. WAVE3, Wiskott-Aldrich syndrome protein family verprolin-homologous protein 3; EMT, epithelial-mesenchymal transition. 
was markedly increased (Fig. 5D). Thus, the knockdown of WAVE3 led to the acquisition of an epithelial-like phenotype from a neural-like phenotype in the pancreatic cancer cell lines (19). Overall, the knockdown of WAVE3 negatively influenced the migratory and invasive capabilities of the PANC-1 and CFPAC-1 cell lines.

Suppression of WAVE3 negatively affects the survival of pancreatic cancer cells. The cell growth curve was generated over 4 consecutive days using the CCK-8 assay. Moreover, plate clone formation assays were conducted to detect the cell survival abilities of the PANC-1 and CFPAC-1 cell lines. WAVE3 played a significant role in cell growth. Following WAVE3 siRNA interference (Si-3), the PANC-1 and CFPAC-1 cell lines exhibited a decrease in cell viability in the CCK-8 assays and poorer cell growth than the control cells in the plate clone formation assays $(\mathrm{P}<0.05)$ (Fig. 6A and $\mathrm{B})$. Flow cytometry demonstrated that the decreased WAVE3 protein expression led to an increased rate of apoptosis of the pancreatic cancer cell lines $(\mathrm{P}<0.05)$ (Fig. 6C). Western blot analysis revealed that the protein level of $\mathrm{p} 53$ increased following the knockdown of WAVE 3 in the PANC-1 and CFPAC- 1 cell lines, while the expression of its downstream protein, $\mathrm{Bcl}-2$, which is inhibited by $\mathrm{p} 53$, was decreased in comparison to that in the control group (Fig. 6D).

WAVE3 affects the cell cycle of pancreatic cancer cells. The role of WAVE3 expression in the pancreatic cancer cell cycle was assessed by flow cytometry. Compared with the control groups, the fraction of cells in the G1 phase increased following the knockdown of WAVE3, while the fraction in $\mathrm{S}$ phase decreased $(\mathrm{P}<0.05)$ (Fig. 7A and $\mathrm{B})$. Thus, the knockdown of WAVE3 induced cell cycle arrest in the G1 phase. To explore the molecular mechanisms involved in the induction of G1 phase caused by WAVE3 knockdown, western blot analysis was conducted to assess the protein expression of cyclin D1, a key cell cycle-regulated protein that influences the G1 phase transition to $\mathrm{S}$ phase. The cyclin D1 protein level decreased after the knockdown of WAVE3 (Fig. 7C). Thus, the G1 phase arrest induced by the knockdown of WAVE3 in pancreatic cancer cell lines was mediated via the downregulation of cyclin D1.

WAVE3 affects the biological behaviors of pancreatic cancer cells via the AKT pathway. Western blot analysis was conducted to determine whether WAVE3 affects the AKT pathway. Following the knockdown of WAVE3 by siRNA (Si-3), the protein expression of PDK2 and p-AKT 473 was decreased compared with that in the control groups in both the PANC-1 and CFPAC-1 cell lines (Fig. 8). Therefore, the knockdown of WAVE3 suppressed the expression of PDK2, thus inhibiting the activation of $\mathrm{p}$-AKT 473 and altering downstream protein expression levels. On the whole, our data indicate that WAVE3 affects the survival, invasion, migration and the cell cycle of pancreatic cancer cell lines (PANC-1 and CFPAC-1) via the AKT pathway (Fig. 9).

\section{Discussion}

Pancreatic cancer is considered a malignant tumor and is associated with high mortality rates even with improved treatment methods (20). Metastasis is the non-negligible cause of a poor prognosis of patients with pancreatic cancer. A series of studies have demonstrated the involvement of EMT in the progression of pancreatic cancer metastasis (21-23). Thus, exploring the mechanisms of EMT in pancreatic cancer is a very important research strategy for the treatment of pancreatic cancer.

The majority of research investigating WAVE3 has demonstrated its overexpression in each cancer type studied, such as ovarian cancer, breast cancer, prostate cancer, hepatocellular carcinoma, gastric cancer and colorectal cancer (6-11). As mentioned previously, some studies have shown that high expression levels of WAVE3 lead to enhanced migratory and invasive capabilities via EMT in certain types of cancer $(10,12)$. In addition, researchers have suggested that WAVE3 is linked to cell survival in certain types of cancer $(6,8,10-12)$. However, the function and molecular mechanisms of WAVE3 in EMT and its association with cell survival remain unclear due to the limited number of studies.

In the present study, the protein expression levels of WAVE3 were significantly higher in pancreatic cancer tissues than in non-cancerous tissues. Furthermore, the clinical data of our retrospective study demonstrated that the overexpression of WAVE3 was associated with lymphatic metastasis $(\mathrm{P}<0.05)$, poorly differentiated tumors $(\mathrm{P}<0.05)$ and high pre-operative CA19-9 levels $(\mathrm{P}<0.05)$ and that the high expression of WAVE3 indicated a poor outcome of patients with pancreatic cancer. In vitro, the WAVE3 expression levels were also markedly higher in the pancreatic cancer cell lines compared with those in a non-neoplastic human pancreatic ductal epithelial cell line. Additionally, a comparison of the different pancreatic cancer cell lines suggested that the WAVE3 expression levels may be associated with cell differentiation and mobility. Thus, we selected PANC-1 (better migration and invasion abilities and higher expression of the WAVE3 protein) and CFPAC-1 (well-differentiated and a lower WAVE3 expression) to conduct the following experiments. Our analysis revealed that the cell migratory and invasive capacities were inhibited following the knockdown of WAVE3. Western blot analysis demonstrated that the knockdown of WAVE3 decreased the expression of certain EMT-related proteins, such as Slug, Snail, Vimentin, ZEB1 and N-Cadherin, and upregulated E-cadherin expression. Thus, the pancreatic cancer cell lines acquired an epithelial-like phenotype from a neural-like phenotype, decreasing their migratory and invasive potentials, following WAVE3 knockdown. WAVE3 suppression decreased the proliferation and increased the apoptosis of the pancreatic cancer cell lines. Flow cytometry revealed that the knockdown of WAVE3 induced cell cycle arrest in the G1 phase. Taken together, the suppression of WAVE3 decreased the proliferation, migration and invasion abilities and increased the apoptosis of the pancreatic cancer cell lines analyzed.

A number of studies have shown that Snail inhibits the expression of E-cadherin, which is closely related to cancer invasion and metastasis via EMT $(24,25)$. The enhancement of AKT activity with Snail stabilization is essential for EMT and, subsequently, improves the invasive and metastatic potential of tumors $(26,27)$. High-intensity p-AKT expression is related to poor outcomes of patients with pancreatic ductal adenocarcinoma (28). The inhibition of the AKT pathway in pancreatic cancer cell lines (PANC-1 and HPAF) shows a promising effect 
A

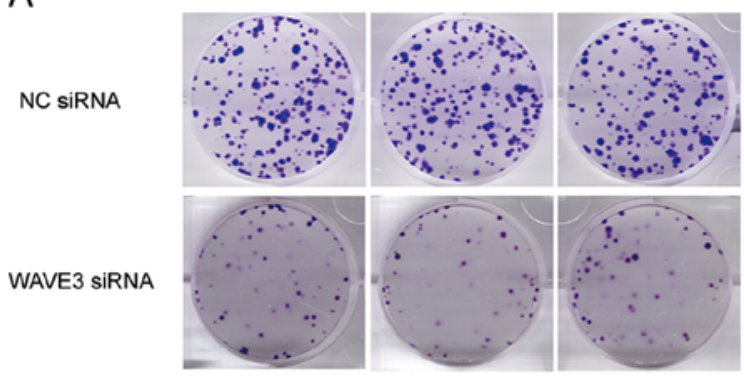

ANC-1

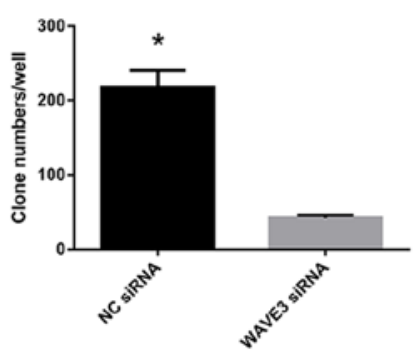

CFPAC-1

NC siRNA
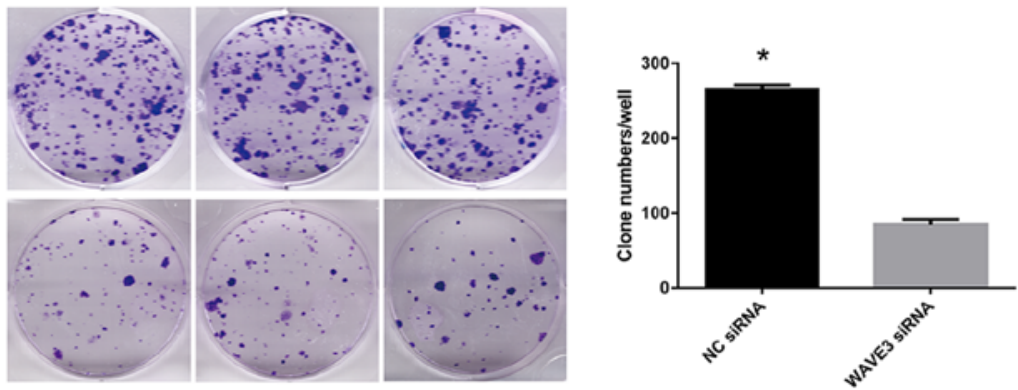

D
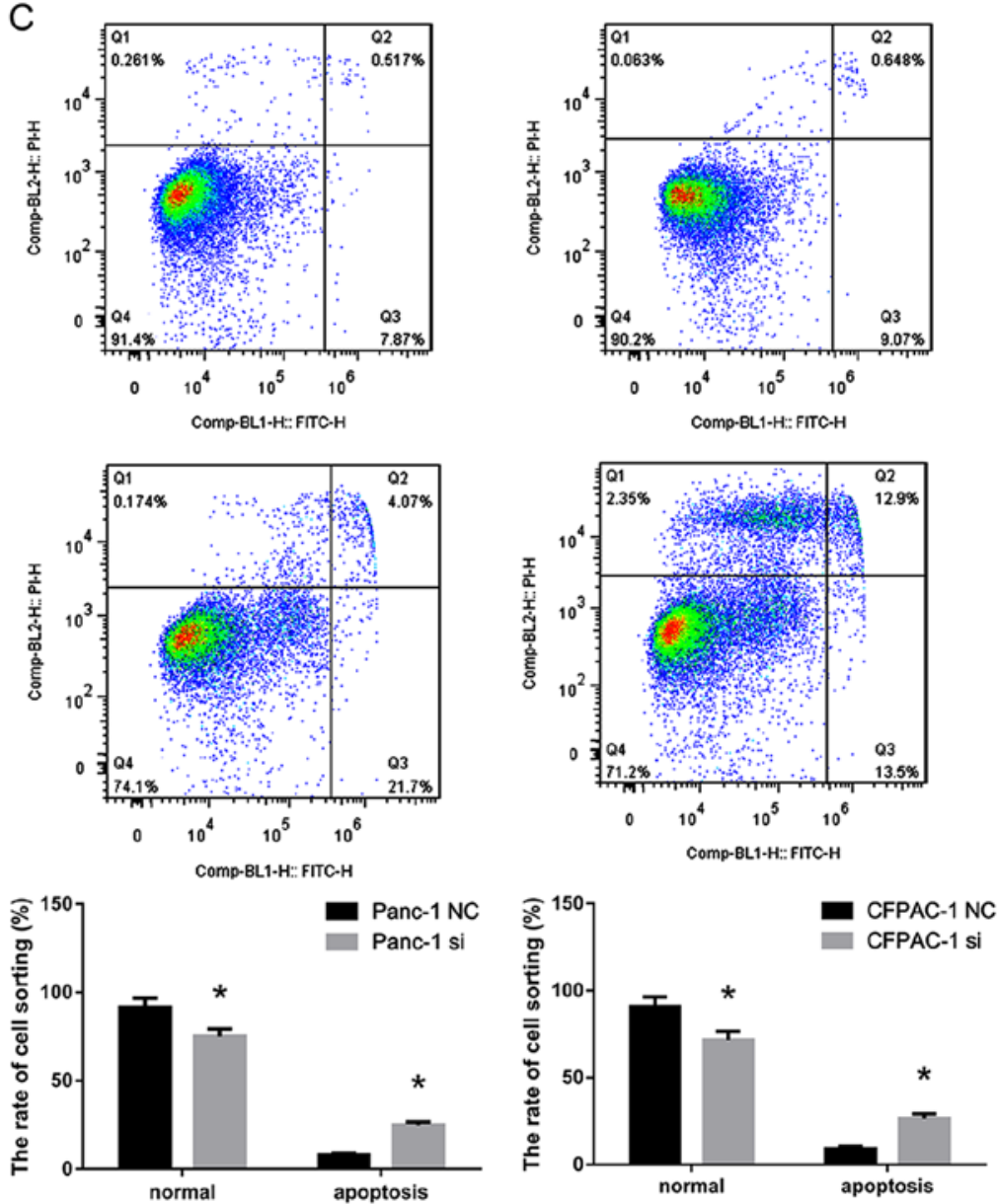

WAVE-3

p53

Bcl-2

GAPDH
B
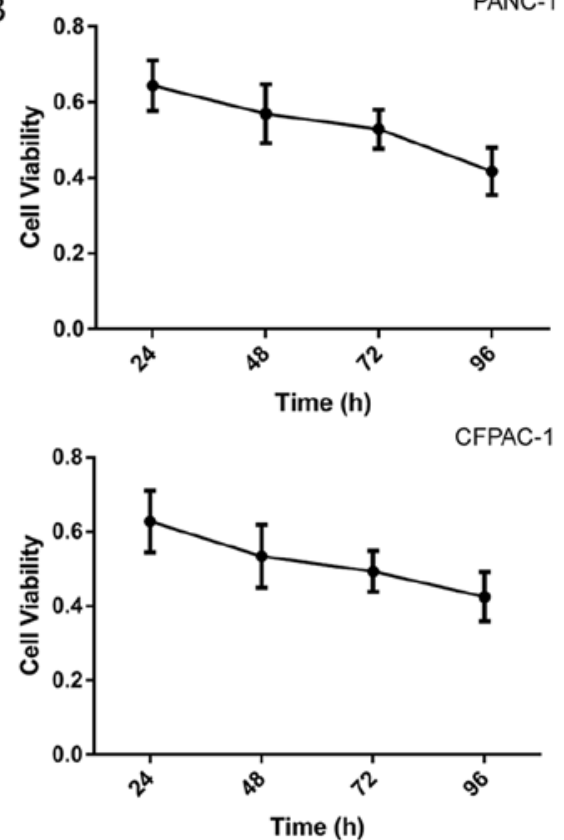
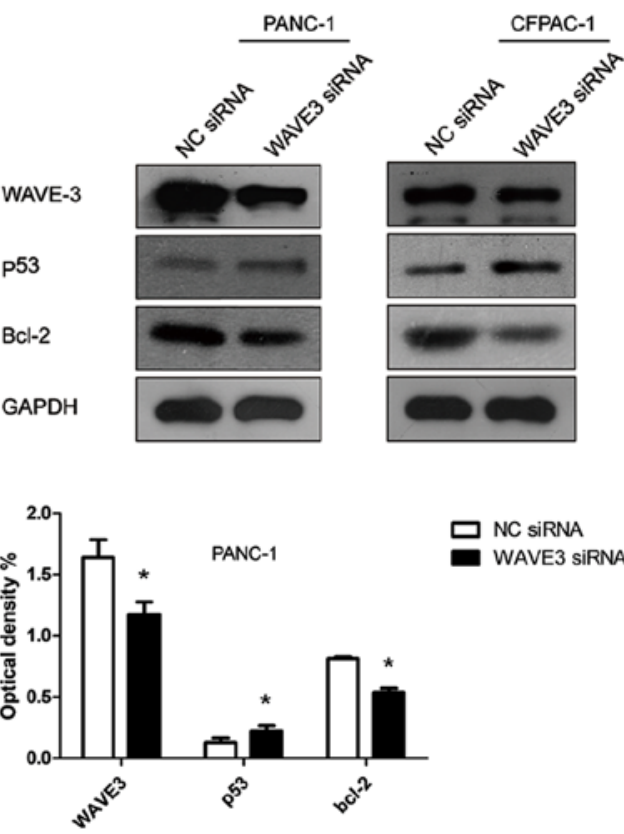

口 NC siRNA

- WAVE3 SIRNA

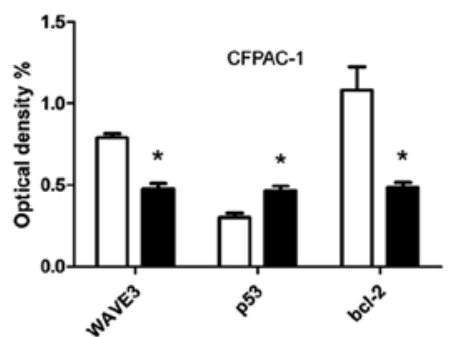

Figure 6. Knockdown of WAVE3 negatively affects the survival of pancreatic cancer cells lines. (A and B) Cell growth potential was inhibited in the pancreatic cancer cell lines following transfection with WAVE3 siRNA, as demonstrated by the plate clone formation and CCK- 8 assays ( $\mathrm{P}<0.05$ vs. the NC siRNA-transfected cells). (C) Flow cytometry demonstrated that the percentages of apoptosis were increased in both cell lines following the knockdown of WAVE3 ( $\mathrm{P}<0.05$ ) (D) Western blot analyses revealed that the expression of cell survival-related proteins (p53 and Bcl-2) was altered following the knockdown of WAVE3 in the PANC-1 and CFPAC-1 cell lines. ${ }^{*} \mathrm{P}<0.05$ vs. the NC siRNA-transfected cells. WAVE3, Wiskott-Aldrich syndrome protein family verprolin-homologous protein.

by reducing cell growth and promoting apoptosis (29). Taken together, from the above-mentioned findings, we hypothesized that WAVE3 influences the proliferation, migration and invasion of pancreatic cancer cell lines via the AKT pathway. 

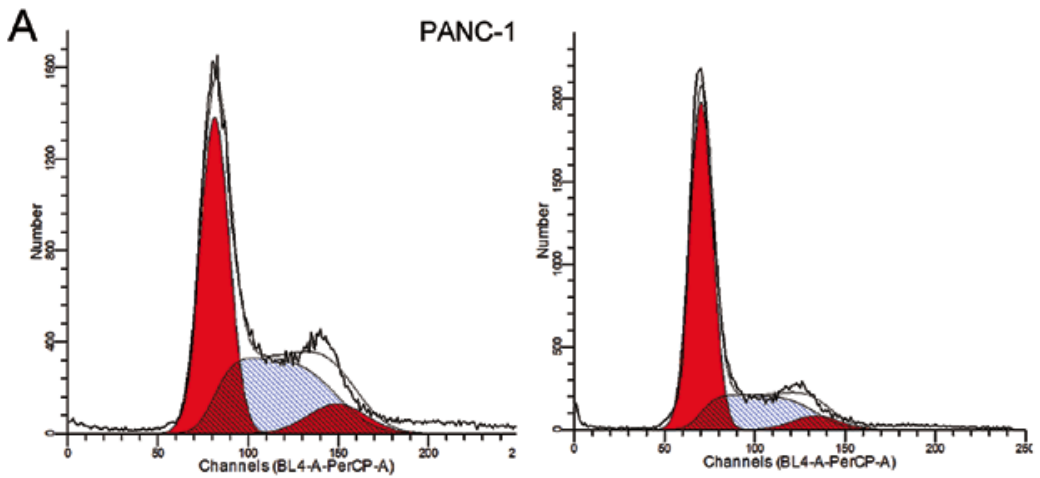

B
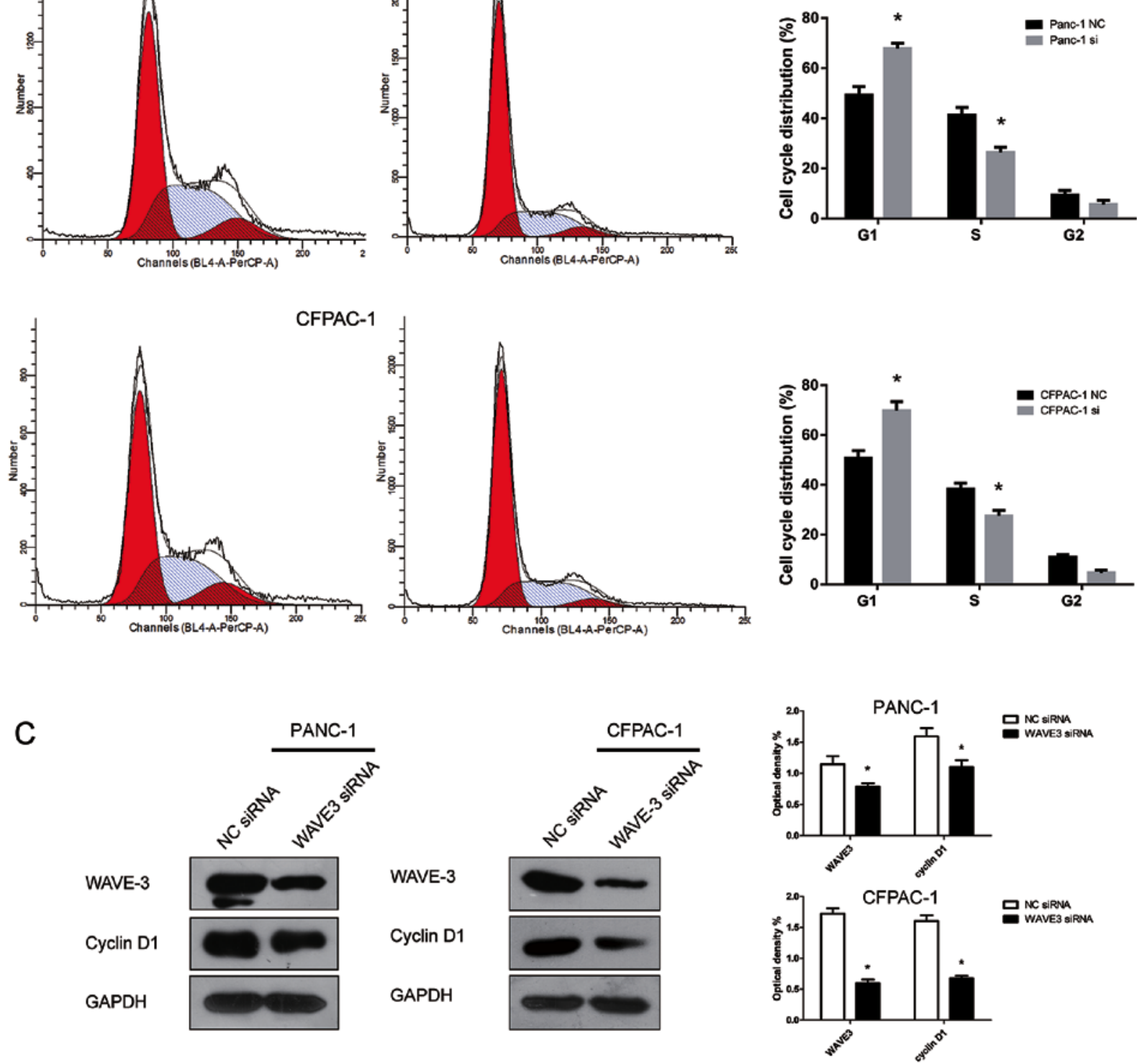

Figure 7. WAVE3 affects the cell cycle. (A and B) Compared with the control group, the number of cells in S phase decreased, while the number of cells in the G1 phase increased in both the PANC-1 and CFPAC-1 cell lines ("P<0.05 vs. the NC siRNA-transfected cells). (C) Western blot analyses showed that the expression of Cyclin D1 decreased after the knockdown of WAVE3 in the pancreatic cancer cell lines. " $\mathrm{P}<0.05$ vs. the NC siRNA-transfected cells. WAVE3, Wiskott-Aldrich syndrome protein family verprolin-homologous protein 3.

To further confirm this hypothesis, western blot analysis was conducted to determine whether WAVE3 affects the AKT pathway to alter the biological behaviors of pancreatic cancer cell lines. The knockdown of WAVE3 decreased the expression of PDK2 and then negatively inhibited the phosphorylation of its downstream molecule, AKT, at the Ser473 site. As a result, the expression of downstream proteins in the AKT pathway was affected, accordingly affectin cell survival, invasion and migration as well as the cell cycle (Fig. 9). The p53 and Bcl-2 proteins downstream of the AKT pathway are known to affect cell survival, and another downstream protein, cyclin D1, influences the cell cycle $(15,30)$. Therefore, western blot analysis was conducted to assess whether the expression levels of p53, Bcl-2 and cyclin D1 were altered following the knockdown of WAVE3. The p53 protein level was increased following the knockdown of WAVE3, while the expression of its downstream protein, Bcl-2, which is inhibited by $\mathrm{p} 53$, was decreased. Moreover, the protein level of cyclin D1 was decreased following the knockdown of WAVE3. This result was consistent with the phenomenon that the knockdown of WAVE3 induced cell cycle arrest in the G1 phase. Taken together, WAVE3 influences the AKT pathway to modify the biological behaviors of pancreatic cancer cell lines.

Previous studies have focused on gene mutations in pancreatic cancer, and certain genes have been shown to be related to pancreatic cancer, including KRAS, ATM (31), TP53, BRAF (32), SMAD4 and CDKN2A (33). The molecular mechanisms of the mutated genes listed above were discovered in several studies (31-33); however, the corresponding novel agents targeting these mutated genes have not been identified. In this study, WAVE3 was regarded as a potential target for the treatment of pancreatic cancer as 


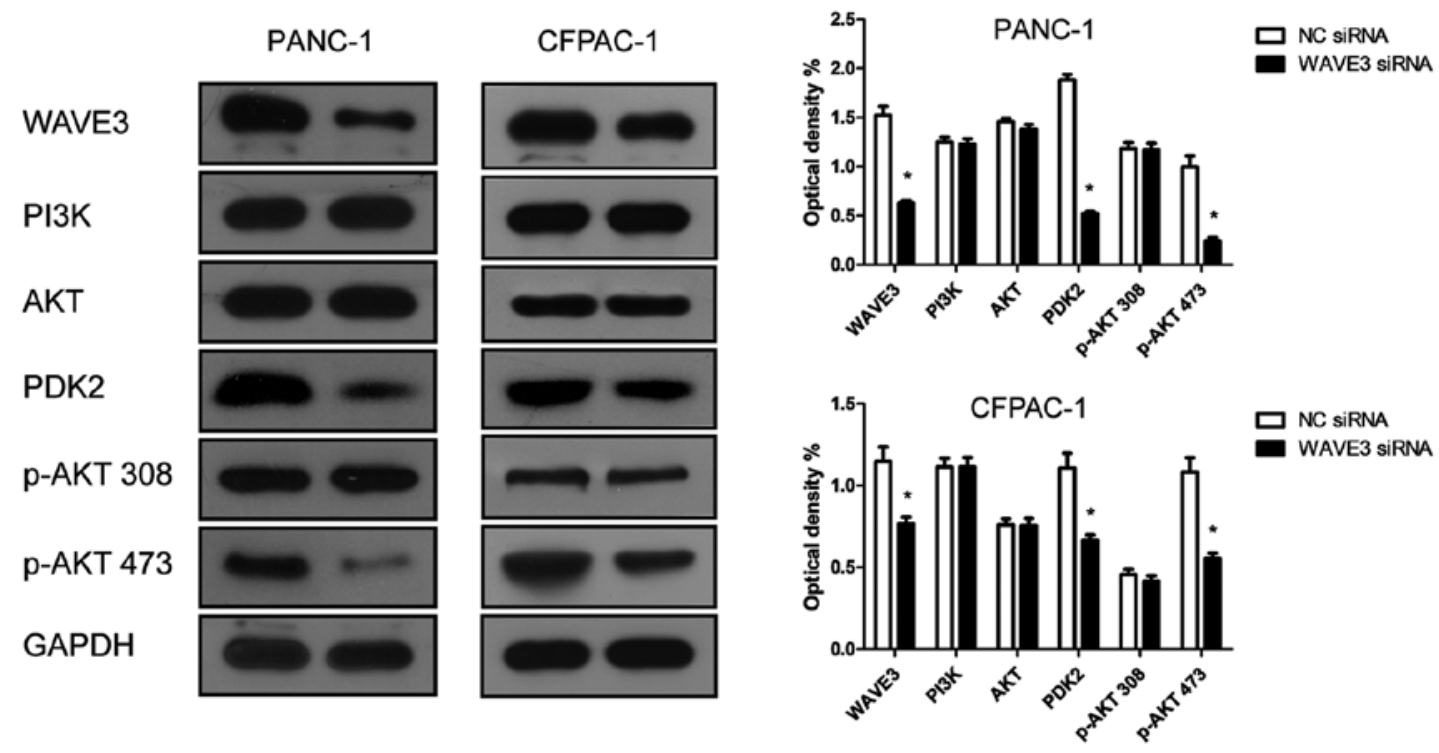

Figure 8. The PDK2 protein expression levels were altered following WAVE3 siRNA interference. Western blot analysis showed that the knockdown of WAVE3 reduced the expression of PDK2 and the activation of p-AKT 473. ${ }^{*}<0.05$ vs. the NC siRNA-transfected cells. PDK2, pyruvate dehydrogenase kinase isoform 2; WAVE3, Wiskott-Aldrich syndrome protein family verprolin-homologous protein 3.

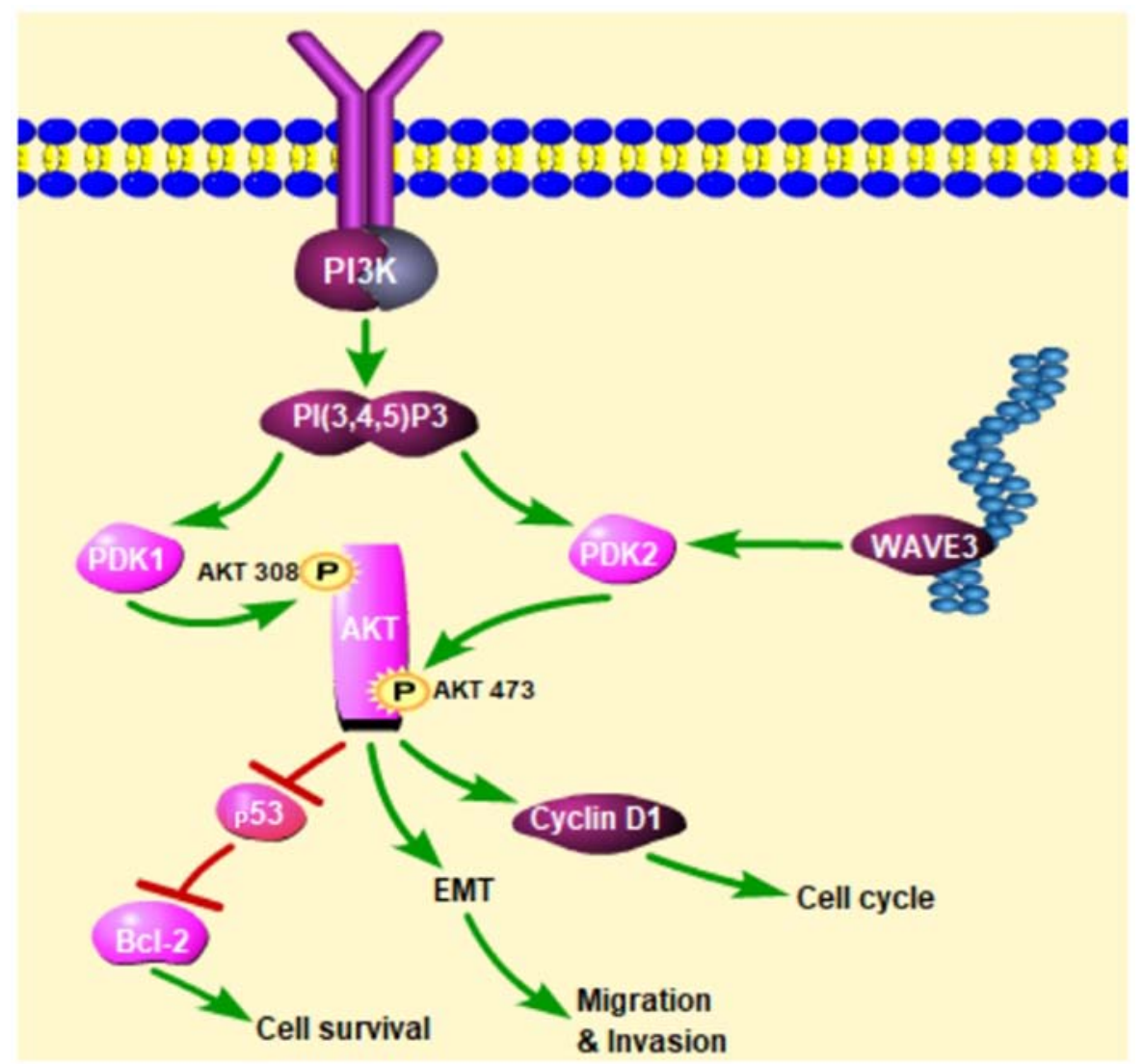

Figure 9. Schematic of the above-mentioned findings. WAVE3 influences cell survival, invasion, migration and the cell cycle of pancreatic cancer cell lines (PANC-1 and CFPAC-1) via the AKT pathway. Furthermore, WAVE3 affects PDK2 to affect the phosphorylation of AKT at Ser473. PDK2, pyruvate dehydrogenase kinase isoform 2; WAVE3, Wiskott-Aldrich syndrome protein family verprolin-homologous protein 3.

we discovered that it influenced the AKT pathway and then significantly affected the biological behaviors of pancreatic cancer cell lines. In this study, the knockdown of WAVE3 reversed the malignant behaviors of pancreatic cell lines. Therefore, novel agents targeted toward WAVE3 and/or the AKT pathway are worth exploring for the treatment of pancreatic cancer.

In conclusion, in this study, we demonstrated that the expression levels of WAVE3 in pancreatic cancer tissues were prominently higher than those in the non-cancerous tissues. 
Our clinical data revealed that the overexpression of WAVE3 was associated with lymphatic metastasis, poorly differentiated tumors and high pre-operative levels of CA19-9. Moreover, a high expression of WAVE3 was associated with a poor prognosis of patients with pancreatic cancer. In the cell culture experiments, the WAVE3 expression levels were markedly higher in the pancreatic cancer cell lines than in a non-neoplastic human pancreatic ductal epithelial cell line. Furthermore, the suppression of WAVE3 inhibited the cell proliferative, migratory and invasive capabilities and promoted the apoptosis of the pancreatic cancer cell lines. The mechanism underlying this phenomenon was WAVE3 knockdown inhibiting PDK2 expression, which negatively affected the phosphorylation of it downstream molecule, AKT, at the Ser473 site. Therapies targeted toward WAVE3 and/or the AKT pathway may be worth exploring for the treatment of pancreatic cancer.

\section{Acknowledgements}

The authors would like to thank Professor Anxun Wang (Department of Oral and Maxillofacial Surgery, the First Affiliated Hospital of Sun Yat-Sen University, Guangzhou, China) for providing technical assistance and Professor Peng Huang (Sun Yat-Sen University Cancer Center, Guangzhou, China) for kindly providing the non-neoplastic human pancreatic ductal epithelial cell line (hTERT-HPNE).

\section{Funding}

No funding was received.

\section{Availability of data and materials}

The datasets used and/or analyzed during the current study are available from the corresponding author on reasonable request.

\section{Authors' contributions}

$\mathrm{CZ}$ proposed the study. $\mathrm{SH}$ and $\mathrm{CH}$ performed the research. WC and YL collected and analyzed the data. XY, JL, LL and QW provided the clinical specimens and clinical data. AW offered the technical assistance. All authors contributed to the conception, design and interpretation of the study and to further drafts. All authors have read and approved the final manuscript.

\section{Ethics approval and consent to participate}

The study was approved by the Institute Research Ethics Committee of the First Affiliated Hospital at Sun Yat-Sen University. As this study is a retrospective study, the patient consent was allowed to be waived by the ethics committee.

\section{Consent for publication}

Not applicable.

\section{Competing interests}

The authors declare that they have no competing interests.

\section{References}

1. Torre LA, Bray F, Siegel RL, Ferlay J, Lortet-Tieulent J and Jemal A: Global cancer statistics, 2012. CA Cancer J Clin 65: 87-108, 2015

2. Wang-Gillam A, Li CP, Bodoky G, Dean A, Shan YS, Jameson G, Macarulla T, Lee KH, Cunningham D, Blanc JF, et al; NAPOLI-1 Study Group: Nanoliposomal irinotecan with fluorouracil and folinic acid in metastatic pancreatic cancer after previous gemcitabine-based therapy (NAPOLI-1): A global, randomised, open-label, phase 3 trial. Lancet 387: 545-557, 2016.

3. Deplanque G and Demartines N: Pancreatic cancer: Are more chemotherapy and surgery needed? Lancet 389: 985-986, 2017.

4. Kamisawa T, Isawa T, Koike M, Tsuruta K and Okamoto A: Hematogenous metastases of pancreatic ductal carcinoma. Pancreas 11: 345-349, 1995.

5. Sossey-Alaoui K: Surfing the big WAVE: Insights into the role of WAVE3 as a driving force in cancer progression and metastasis. Semin Cell Dev Biol 24: 287-297, 2013.

6. Lu J, Wang SL, Wang YC, Wu YN, Yu X, Zhao WZ and Wang JH: High WAVE3 expression correlates with proliferation, migration and invasion in human ovarian cancer. Oncotarget 8: 41189-41201, 2017.

7. Davuluri G, Schiemann WP, Plow EF and Sossey-Alaoui K: Loss of WAVE3 sensitizes triple-negative breast cancers to chemotherapeutics by inhibiting the STAT-HIF-1 $\alpha$-mediated angiogenesis. JAK-STAT 3: e1009276, 2015.

8. Moazzam M, Ye L, Sun PH, Kynaston H and Jiang WG: Knockdown of WAVE3 impairs HGF induced migration and invasion of prostate cancer cells. Cancer Cell Int 15: 51, 2015.

9. Ji Y, Li B, Zhu Z, Guo X, He W, Fan Z and Zhang W: Overexpression of WAVE3 promotes tumor invasiveness and confers an unfavorable prognosis in human hepatocellular carcinoma. Biomed Pharmacother 69: 409-415, 2015.

10. Yue Z, Feng W, Xiangke L, Liuxing W, Qingxia F and Jianbo G: WAVE3 promotes epithelial-mesenchymal transition of gastric cancer through upregulation of Snail. Cancer Gene Ther 21: 499-506, 2014.

11. Zhang Y, Guan XY, Dong B, Zhao M, Wu JH, Tian XY and Hao CY: Expression of MMP-9 and WAVE3 in colorectal cancer and its relationship to clinicopathological features. J Cancer Res Clin Oncol 138: 2035-2044, 2012.

12. Taylor MA, Davuluri G, Parvani JG, Schiemann BJ, Wendt MK, Plow EF, Schiemann WP and Sossey-Alaoui K: Upregulated WAVE3 expression is essential for TGF- $\beta$-mediated EMT and metastasis of triple-negative breast cancer cells. Breast Cancer Res Treat 142: 341-353, 2013.

13. Sossey-Alaoui K, Ranalli TA, Li X, Bakin AV and Cowell JK: WAVE3 promotes cell motility and invasion through the regulation of MMP-1, MMP-3, and MMP-9 expression. Exp Cell Res 308: 135-145, 2005.

14. Osaki M, Oshimura M and Ito H: PI3K-Akt pathway: Its functions and alterations in human cancer. Apoptosis 9: 667-676, 2004.

15. Manning BD and Cantley LC: AKT/PKB signaling: Navigating downstream. Cell 129: 1261-1274, 2007.

16. Edge SB: American Joint Committee on Cancer; ACS. In: AJCC Cancer Staging Manual. 7th edition. Springer, New York, 2009.

17. Chang B, Li S, He Q, Liu Z, Zhao L, Zhao T and Wang A: Deregulation of Bmi-1 is associated with enhanced migration, invasion and poor prognosis in salivary adenoid cystic carcinoma. Biochim Biophys Acta 1840: 3285-3291, 2014.

18. Deer EL, González-Hernández J, Coursen JD, Shea JE, Ngatia J, Scaife CL, Firpo MA and Mulvihill SJ: Phenotype and genotype of pancreatic cancer cell lines. Pancreas 39: 425-435, 2010.

19. Thiery JP, Acloque H, Huang RY and Nieto MA: Epithelialmesenchymal transitions in development and disease. Cell 139: 871-890, 2009.

20. Middleton G, Palmer DH, Greenhalf W, Ghaneh P, Jackson R, Cox T, Evans A, Shaw VE, Wadsley J, Valle JW, et al: Vandetanib plus gemcitabine versus placebo plus gemcitabine in locally advanced or metastatic pancreatic carcinoma (ViP): A prospective, randomised, double-blind, multicentre phase 2 trial. Lancet Oncol 18: 486-499, 2017.

21. Rhim AD,MirekET,Aiello NM,Maitra A,Bailey JM,McAllisterF, Reichert M, Beatty GL, Rustgi AK, Vonderheide RH, et al: EMT and dissemination precede pancreatic tumor formation. Cell 148: 349-361, 2012.

22. Hao K, Tian XD, Qin CF, Xie XH and Yang YM: Hedgehog signaling pathway regulates human pancreatic cancer cell proliferation and metastasis. Oncol Rep 29: 1124-1132, 2013. 
23. Bo H, Zhang S, Gao L, Chen Y, Zhang J, Chang X and Zhu M: Upregulation of Wnt5a promotes epithelial-to-mesenchymal transition and metastasis of pancreatic cancer cells. BMC Cancer 13: 496, 2013.

24. Yang MH, Chen CL, Chau GY, Chiou SH, Su CW, Chou TY, Peng WL and Wu JC: Comprehensive analysis of the independent effect of twist and snail in promoting metastasis of hepatocellular carcinoma. Hepatology 50: 1464-1474, 2009.

25. Oda H, Tsukita $\mathrm{S}$ and Takeichi M: Dynamic behavior of the cadherin-based cell-cell adhesion system during Drosophila gastrulation. Dev Biol 203: 435-450, 1998.

26. Liu L, Dai Y, Chen J, Zeng T, Li Y, Chen L, Zhu YH, Li J, Li Y, Ma S, et al: Maelstrom promotes hepatocellular carcinoma metastasis by inducing epithelial-mesenchymal transition by way of Akt/GSK-3ß/Snail signaling. Hepatology 59: 531-543, 2014.

27. Liu A, Shao C, Jin G, Liu R, Hao J, Song B, Ouyang L and $\mathrm{Hu}$ X: miR-208-induced epithelial to mesenchymal transition of pancreatic cancer cells promotes cell metastasis and invasion. Cell Biochem Biophys 69: 341-346, 2014.

28. Yamamoto S, Tomita Y, Hoshida Y, Morooka T, Nagano H, Dono K, Umeshita K, Sakon M, Ishikawa O, Ohigashi H, et al: Prognostic significance of activated Akt expression in pancreatic ductal adenocarcinoma. Clin Cancer Res 10: 2846-2850, 2004.

29. Stoll V, Calleja V, Vassaux G, Downward J and Lemoine NR Dominant negative inhibitors of signalling through the phosphoinositol 3-kinase pathway for gene therapy of pancreatic cancer. Gut 54: 109-116, 2005.
30. Tang F, Wang Y, Hemmings BA, Rüegg C and Xue G: $\mathrm{PKB} / \mathrm{Akt}$-dependent regulation of inflammation in cancer. Semin Cancer Biol 48: 62-69, 2018.

31. Biankin AV, Waddell N, Kassahn KS, Gingras MC, MuthuswamyLB, Johns AL, Miller DK, Wilson PJ, Patch AM, Wu J, et al; Australian Pancreatic Cancer Genome Initiative: Pancreatic cancer genomes reveal aberrations in axon guidance pathway genes. Nature 491: 399-405, 2012.

32. Raphael BJ, Hruban RH, Aguirre AJ, Moffitt RA, Yeh JJ, Stewart C, Robertson AG, Cherniack AD, Gupta M, Getz G, et al; Cancer Genome Atlas Research Network: Integrated Genomic Characterization of Pancreatic Ductal Adenocarcinoma. Cancer Cell 32: 185-203.e13, 2017.

33. Waddell N, Pajic M, Patch AM, Chang DK, Kassahn KS, Bailey P, Johns AL, Miller D, Nones K, Quek K, et al; Australian Pancreatic Cancer Genome Initiative: Whole genomes redefine the mutational landscape of pancreatic cancer. Nature 518: 495-501, 2015.

This work is licensed under a Creative Common Attribution-NonCommercial-NoDerivatives 4.0 International (CC BY-NC-ND 4.0) License. 